\title{
Emergency cricothyrotomy: temporary measure or definitive airway? A systematic review.
}

\section{Cricotireoidostomia de emergência: medida contemporizadora ou via aérea definitiva? Uma revisão sistemática.}

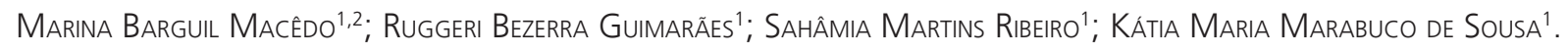

\begin{abstract}
A B S T R A C T
Being a fast and safe method in the hands of well trained professionals in both prehospital and intrahospital care, Cricothyrotomy has been broadly recommended as the initial surgical airway in the scenario "can't intubate, can't ventilate", and is particularly useful when the obstruction level is above or at the glottis. Its prolonged permanence, however, is an endless source of controversy. In this review we evaluate the complications of cricothyrotomy and the need of its routine conversion to tracheotomy through a search on PubMed, LILACS and SCIELO electronic databases with no restriction to the year or language of the publication. In total, we identified 791 references, retrieved 20 full text articles, and included nine studies in our review. The incidence of short-term complications ranged from zero to $31.6 \%$, and the long-term complications, from zero to $7.86 \%$. Subglotic stenosis was the main long-term reported complication, even though it was quite infrequent, occurring only in 2.9 to 5\%. The frequency of conversion to tracheostomy varied from zero to $100 \%$. Although a small frequency of long-term complications was found for emergency cricothyrotomy, the studies' low level of evidence does not allow the recommendation of routine use of cricothyrotomy as a secure definitive airway.
\end{abstract}

Keywords: Cricoid Cartilage. Airway Management. Advanced Trauma Life Support Care. Evidence-Based Emergency Medicine.

\section{INTRODUCTION}

$T^{\mathrm{T}}$ he early establishment of a safe airway is a basic principle of life support. Patient background, clinical scenario and professionals' abilities all play an important role on the achievement of a patent airway ${ }^{1,2}$. According to the American Society of Anesthesiologists, a difficult airway is "the clinical situation in which a conventionally trained anesthesiologist experiences difficulty with facemask ventilation of the upper airway, difficulty with tracheal intubation, or both" 3 .

Endotracheal intubation (EI) is the preferable initial airway for trauma patients who present with apnea, reduced consciousness level, or imminent compromise of the airways. When El cannot be achieved or is contraindicated, a surgical airway technique must be employed, especially for those patients in whom airway adjuncts, such as laryngeal mask and combitube, were tried and failed, or who suffered extensive maxillofacial or neck trauma ${ }^{4-6}$.
Surgical airway procedures include surgical cricothyrotomy and tracheotomy. Cricothyrotomy, being a fast and safe method inthe hands of well trained professionals inboth prehospital and intrahospital care, has been broadly recommended as the initial surgical airway in view of the situation "can't intubate, can't ventilate". It is a particularly useful technique when the obstruction level is above or at the glottis. Its prolonged permanence, however, is an endless source of controversy. Some authors defend that it must be converted to a tracheotomy in 24-72 hours after the initial procedure, due to the associated risk of subglottic stenosis. Yet, conversion is not always possible on unstable and critically ill patients. Reports about patients with such a profile have demonstrated that, contrary to the classically established, cricothyrotomy may be well tolerated by long-term users, with acceptable complication rates ${ }^{1,2,4}$.

Due to the inexistence of a systematic, indepth and recent revision on such a relevant and pertinent theme, we aimed to assess the intraoperative

1 - Federal University of Piauí, Piauí University Hospital, Teresina, Piauí State, Brazil. 2 - University of São Paulo, Department of Immunology, Institute of Biomedical Sciences IV, São Paulo, São Paulo State, Brazil. 
and postoperative complications rates of emergency surgical cricothyrotomy, as well as to evaluate the need of its routine conversion to tracheotomy.

\section{METHODS}

\section{Search strategy}

We inserted the terms "cricothyrotomy", "cricothyroidotomy", and "coniotomy" on Pubmed's search tool. We also inserted the same terms, followed by their cognates in Portuguese, "cricotireoidotomia", "cricotireoidostomia", "cricotirostomia", "cricotireoidostomia", "cricostomia", and "cricotireoidostomia", and in Spanish, "cricotireoidotomía", "cricotireoidostomía", "cricotirostomía", "cricotomía", "cricostomía", and "cricotirotomía", on the search tool of Scielo and LILACS databases.

\section{Inclusion criteria}

We selected for further analysis all the abstracts retrieved by the search strategy up to January $8^{\text {th }}, 2016$, and whose full text were available on the electronic version of the journal in which they were published. We applied no restriction to the year or language of publication.

\section{Exclusion criteria}

We excluded the studies that focused on: 1) cricothyrotomy performed in a non-emergency setting; 2) cricothyrotomy executed on mannequins, cadavers, experimentation animals or virtual simulators; 3) the procedure's teaching methodology and learning curve; 4) techniques or equipments comparison; and 5) the procedure's time of execution or success rate, without mention to intra or postoperative complications,

\section{Data analysis}

On the studies that met the inclusion criteria, we analyzed the following variables: study design; number of cricothyrotomies performed per study; patients' mean age; indication of the procedure, broadly categorized as "trauma" and "non-trauma"; setting in which the procedure was performed, whether "prehospital" or "hospital"; professional responsible for the execution of the procedure, categorized as "nurse", "paramedics", and "physician"; mean time of patient follow-up; cricothyrotomy complications, classified as "short-term complications", when manifested during or immediately after the procedure's execution, or "long-term complications", when manifested several hours to months after the procedure, and subclassified as "minor", when evolving to spontaneous remission and/or not requiring intervention and/or not persisting chronically, or "major", when requiring intervention and/or persisting chronically; number of conversions to tracheotomy; and period of time after which the conversion was done, when applicable.

\section{Assessment of evidence quality}

The selected studies were evaluated by their level of evidence, under the criteria of the Oxford Centre for Evidence-Based Medicine (2009).

\section{RESULTS}

Our search retrieved 23 references on LILACS, 66 references on Scielo and 702 references on Pubmed, totalizing 791. We selected 20 studies fortext reading, and from those, included nine in our review. The included studies were published between 1982 and 2012. Evidence level ranged from $3 b^{7,8}$ to $4^{9-15}$. All studies were retrospective (Table 1$)$. The number of cricothyrotomies per study ranged from 10 to 95 (mean 35), totalizing 316 cricothyrotomies. Patients mean age varied from 32 to 50 years-old (mean 41). The indication for the procedure was a traumatic event in the majority of studies. In three studies ${ }^{10,11,13}$, cricothyrotomy was performed only at a prehospital setting, while in other three ${ }^{7,9,12}$, it was performed only at a hospital setting, and in the remaining three $8,14,15$, in both prehospital and hospital settings. In all except two studies ${ }^{11,13}$, physicians were the professional responsible for the procedure. Patients received long term follow-up in five studies ${ }^{7-10,12}$, but only two $0^{8,12}$ described the follow-up average time, which ranged between 23 and 51 months. Short-term complications varied from zero (in one third of studies) to $31.6 \%$, and long-term complications varied from zero (in $40 \%$ of studies) to $7.86 \%$. Conversion of cricothyrotomy to 


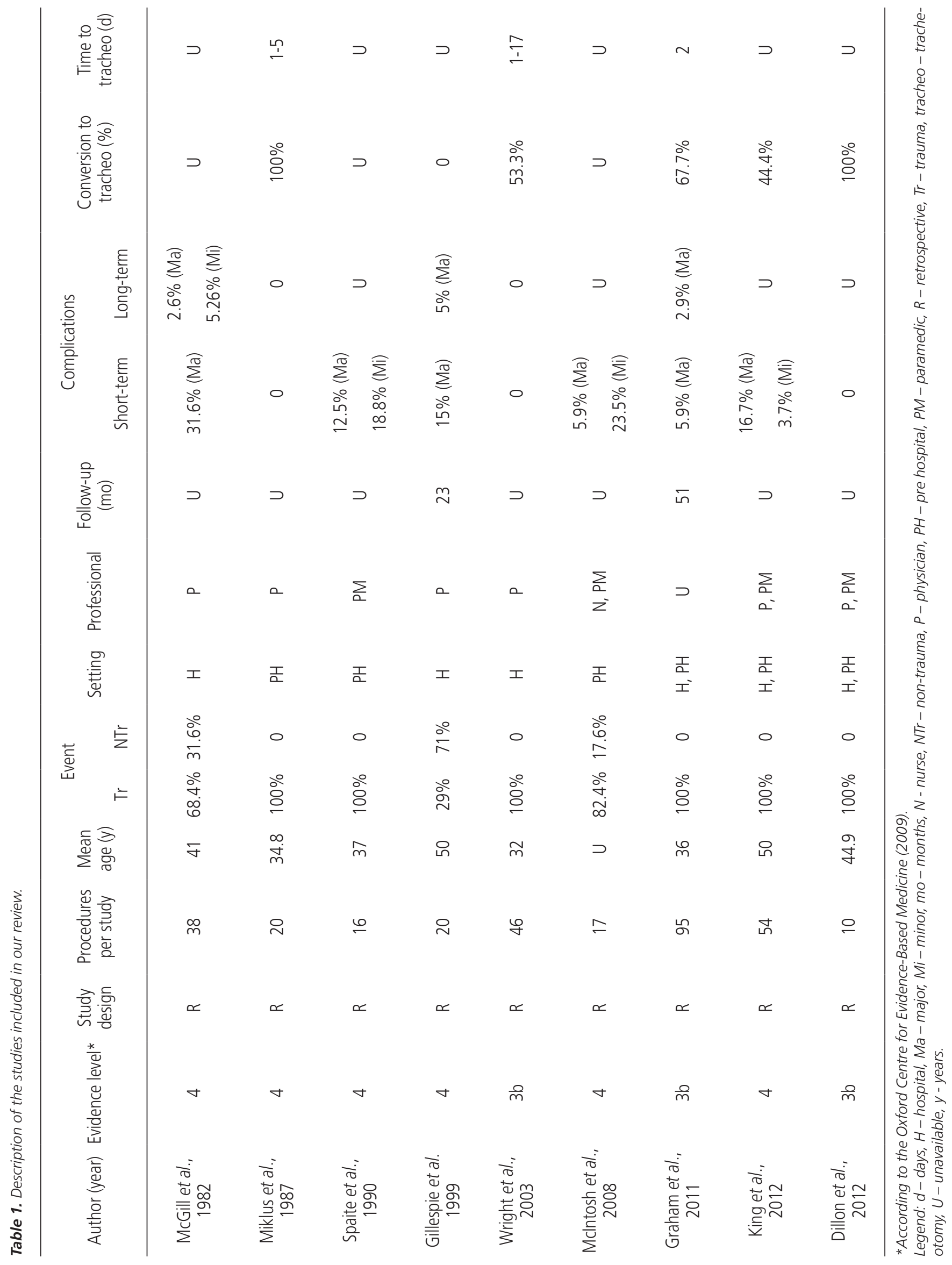


tracheotomy was mentioned in six studies $7,8,10,12,14,15$ but was carried outin all patients in only two of them ${ }^{10,15}$. Time from cricothyrotomy to tracheotomy ranged from one to 17 days.

\section{DISCUSSION}

From the end of the $19^{\text {th }}$ Century onwards, several attempts of systematization and standardization of airway management in critical patients were carried out to establish the safety of executed procedures, special attention being given to the study of their complications. In this context, Chevalier Jackson published a series of 200 cases of subglottic stenosis in 1921. All cases were secondary to the establishment of an airway, and 158 patients had undergone cricothyrotomy, referred as "high tracheotomy" by the author. He thus concluded that cricothyrotomy offered an alarming high risk of complications in comparison to conventional tracheotomy, as he stressed that those patients had no known previous inflammatory airway disease which could explain the high rates of subglottic stenosis ${ }^{16}$.

Later, it was pointed out that some of the observed complications were due to the technique employed at the time, when airway was accessed through the thyroid cartilage, and not through the cricoid. Brantigan and Grow were the first to adopt a critical view of the results presented by Jackson and to introduce evidence contradicting his statements. In 1976, they published a study with 655 patients who underwent cricothyrotomy. Only $6.1 \%$ of those had complications, and none developed subglottic stenosis. They concluded that elective surgical cricothyrotomy complications were neither more severe nor more frequent than the complications after conventional tracheotomy ${ }^{17}$. After this, several subsequent studies continued on questioning the excessively high rate of subglottic stenosis described by Jackson.

In a prospective study performed by François et al, in 2003, 118 patients from an Intensive Care Unit who had their airway secured by means of either tracheotomy or surgical cricothyrotomy were followed up for six months, comparing and the incidence and severity of each technique's complications. Complications were classified as immediate (pneumothorax, bleeding, difficult cannulation), early (subglottic stenosis, acute respiratory failure, tracheoesophageal fistula, temporary or chronic dysfunction of vocal cords), or late (tracheal granuloma, non-healing wounds, and scars) ${ }^{18}$.

Immediate complications, especially moderate bleedings, were more frequent on patients who underwent tracheotomy, which was justified by the presence of bleeding disorders in a greater number of such patients. However, all complications accounted for, they did not find a statistically significant difference between groups. Based on this, François et al stated that cricothyrotomy, being a more easily executed procedure, could be an invaluable alternative to conventional tracheotomy on the airway management of critically ill patients ${ }^{18}$.

Cricothyrotomy has been accepted as the preferred surgical emergency airway on the scenario "can't intubate, can't ventilate" for its technical simplicity and fast accomplishment. The operative field of cricothyrotomy comprehends less noble structures of the neck than the one of tracheotomy. Tracheal cartilaginous rings are not complete, leaving the posterior wall of the trachea and the esophagus unprotected. Such anatomic structures are at greater risk of being inadvertently injured during the execution of tracheotomy. On the other hand, laryngeal and cricoid cartilages have the shape of a complete circumference, acting as a shield to the structures located posterior to them. Also, the incision of tracheotomy is placed more inferior than that of cricothyrotomy, so that the chance of pneumothorax, great vessels injury, or mediastinal perforation are greater ${ }^{1,10}$.

Although it is generally accepted that cricothyrotomy is preferable to tracheotomy in an emergency situation, it is also routinely recommended that, once obtained, the airway must be secured with tracheotomy. For those who defend this position, conversion should be performed as soon as possible, as it would reduce the long-term complication rate associated with cricothyrotomy. Also alleged is that the conversion procedure itself carries minimal risks, comparable to those of elective tracheotomy'.

Up to now, nevertheless, there are no published studies about complications derived from the conversion 
itself. Two of the studies included in our review compared the permanence of cricothyrotomy with conversion to tracheotomy, and both concluded that conversion does not offer any benefit with regards to long-term complications $8^{8,15,19}$.

In 2010, Talving et al reviewed 20 case series of emergency cricothyrotomy performed on trauma patients. They concluded that, despite being a safe initial airway, long term cricothyrotomy remained controversial. The review also underlined the absence of studies proving the benefits of routine conversion. The relevance of such statements, however, was impaired by the methodological deficiencies of the series included on their review ${ }^{4}$.

In our review, we included nine case series, three of which reported a complication rate of zero. The most frequent major short-term complications were, first, the incorrect execution of the technique, resulting in injury of cartilaginous structures on the operative field, reported in five studies ${ }^{10-14}$, and second, the failure of obtaining an airway, reported in two studies ${ }^{9,11}$. Taking into account that cricothyrotomy is indicated for patients in whom other procedures to secure the airway failed, or who present with some degree of anatomical distortion on the neck, it is not surprising that those are the main reported complications.

The broad variability on the complication rate, zero to $31.6 \%$, might be influenced by the experience of the professional who executed the procedure, as well as by logistic issues of the setting in which it was performed. On the series published by King et al (2012), for example, all cricothyrotomies executed by paramedics evolved with immediate complications, while only $10 \%$ of those executed by surgeons had a similar outcome ${ }^{14}$. This finding is consistent with other studies, which reported higher rates of morbidity and mortality on prehospital procedures ${ }^{20-23}$. Because of this, there are authors who suggest cricothyrotomy should notbe performed on a prehospital setting, and patients should be ventilated with bag valve mask until arrival at the nearest trauma center.

However, this contradicts the results of the case series published by Spaite et al (1999), in which he demonstrated that only $12.5 \%$ of the prehospital cricothyrotomies performed by paramedic personnel evolved with major immediate complications. In his study, however, paramedics were submitted to yearly training and to strict supervision of physicians through mobile devices ${ }^{11}$. The nearness of the professional with the procedure, the anatomical points of reference and the different clinical scenarios that he/she could come across, are therefore essential to the reduction of short- and long-term complication rates.

The long-term complication most frequently reported, as expected, was subglottic stenosis, cited in two of the five studies that included patients' follow-up ${ }^{8,12}$. Yet, in general, long-term complications were rather infrequent, ranging from zero to $5.26 \%$, notably lower than the short-term complication rates. One could thereby infer that post-cricothyrotomy adverse events are mainly self-limited or present a satisfactory outcome after a brief intervention, not leaving sequelae. This inference cannot, however, be validated by the present review, since the followup time of the majority of the series included might have been excessively short for the long-term complications to fully manifest themselves. It is known that subglottic stenosis has an insidious presentation, and in accordance to this, the two series that reported this complication were the ones that followed up the patients for longer time.

As an important limitation, our review presents the reduced number of included studies. Even though we have chosengeneric search terms, comprised simply by the name of the procedure and its synonyms, very few studies matched our selection criteria, pointing out to the scarcity of published studies about this theme.

The small number of procedures per study also hampered the achievement of consistent conclusions. Such caveat was foreseen and expected, as emergency cricothyrotomy is a procedure of exception, used as a last resource to obtain airway patency ${ }^{3}$.

Also to be considered are the limitations inherent to the study design. None of the included studies was prospective, multicentric and randomized. Most were case series, so that the quality of evidence obtained prevents categorical recommendations. This was already anticipated, since ethic and legal issues involving the management of critically-ill patients 
impose profound methodological restrictions on studies about emergency cricothyrotomy, as mentioned by another review ${ }^{4}$.

The low level of evidence of the included studies does not permit deeming emergency cricothyrotomy a safe long-term airway. The assembled data suggests, though, that the procedure's long-term severe complications, notably subglottic stenosis, are not as frequent as surmised. Controlled, prospective studies with a larger sample are necessary to elucidate whether emergency cricothyrotomy can be considered a safe definitive airway.

\section{R E S U M O}

A cricotireoidostomia, por ser um método rápido e, em geral, realizado com sucesso em ambientes pré e intra-hospitalares por profissionais treinados, tem sido amplamente preconizada como a via aérea cirúrgica inicial diante da situação "impossível intubar, impossível ventilar" e é especificamente útil quando a obstrução das vias aéreas ocorre na glote ou em nível supraglótico. Seu uso prolongado é, contudo, controverso. Nesta revisão procuramos avaliar as complicações da cricotireoidostomia de emergência, bem como, a necessidade rotineira de sua posterior conversão para traqueostomia através de pesquisa de estudos publicados sobre cricotireoidostomia de emergência nas bases de dados PubMed, LILACS e SciELO, sem restrição quanto ao ano de publicação. Assim foram identificados 791 estudos, dos quais 20 foram selecionados para leitura do texto integral, e, destes, nove foram inclú́dos nesta revisão. A taxa de complicações em curto prazo variou de zero a 31,6\%, e a de complicações em longo prazo variou de zero a 7,86\%. A estenose subglótica foi a principal complicação em longo prazo, relatada em 2,9 a $5 \%$ dos procedimentos. A taxa de conversão para traqueostomia variou de zero a 100\%. Apesar da incidência reduzida de complicações em longo prazo o baixo nível de evidência dos estudos revisados não permite recomendar a cricotireoidostomia como uma via aérea definitiva segura.

Descritores: Cartilagem Cricoide. Manuseio das Vias Aéreas. Cuidados de Suporte Avançado de Vida no Trauma. Medicina de Emergência Baseada em Evidências.

\section{REFERENCES}

1. Hart KL, Thompson SH. Emergency cricothyrotomy. Atlas Oral Maxillofac Surg Clin North AM. 2010;18(1):29-38.

2. Sant'Anna F, Rossi MA, Cerqueira A, Fernandes ACS. Cricotireotomia no manejo de obstrução aguda das vias aéreas. Rev Cir Traumatol Buco-Maxilo-fac. 2010;10(2):35-41.

3. Apfelbaum JL, Hagberg CA, Caplan RA, Blitt CD, Connis RT, Nickinovich DG, et al. Practice guidelines for management of the difficult airway: an updated report by the American Society of Anesthesiologists Task Force on Management of the Difficult Airway. Anesthesiology. 2013;118(2):251-70.

4. Talving P, DuBose J, Inaba K, Demetriades D. Conversion of emergent cricothyrotomy to tracheotomy in trauma patients. Arch Surg. 2010;145(1):87-91.

5. Langvad S, Hyldmo PK, Nakstad AR, Vist GE, Sandberg M. Emergency cricothyrotomy--a systematic review. Scand J Trauma, Resusc Emerg Med. 2013;21(43):1-14.

6. Combes X, Jabre P, Amathieu R, Abdi W, Luis D, Sebbah $J \mathrm{~L}$, et al. Cricothyroïdotomie en situation d'urgence: évaluation d'un scenario dynamique as- sociant intubation et ventilation impossibles. Ann Frd'Anesthésieet de Réanimation. 2011;30(2):1136.

7. Wright MJ, Greenberg DE, Hunt JP, Madan AK, McSwain Jr NE. Surgical cricothyroidotomy in trauma patients. South Med J. 2003;96(5):465-7.

8. Graham DB, Eastman AL, Aldy KN, Carroll EA, Minei JP, Brakenridge SC, et al. Outcomes and long term follow-up after emergent cricothyroidotomy: is routine conversion to tracheostomy necessary? Am Surg. 2011;77(12):1707-11.

9. McGill J, Clinton JE, Ruiz E. Cricothyrotomy in the emergency department. Ann Emerg Med. 1982;11(7):361-4.

10. Miklus RM, Lentz C, Snow N. Surgical cricothyrotomy in the field: experience of a helicopter transport team. Air Medical J. 1987;2(5):24-5.

11. Spaite DW, Joseph M. Prehospital cricothyrotomy: an investigation of indications, technique, complications, and patient outcome. Ann Emerg Med. 1990;19(3):279-85.

12. Gillespie MB, Eisele DW. Outcomes of emergency surgical airway procedures in a hospital-wide setting. Laryngoscope. 1999;109(11):1766-9.

13. Mclntosh SE, Swanson ER, Barton ED. Crico- 
thyrotomy in air medical transport. J Trauma. 2008;64(6):1543-7.

14. King D, Ogilvie M, Michailidou M, Velmahos G, Alam $\mathrm{H}$, deMoya $M$, et al. Fifty-four emergent cricothyroidotomies: are surgeons reluctant teachers? Scani J Surg. 2012;101(1):13-5.

15. Dillon JK, Christensen B, Fairbanks T, Jurkovich G, Moe KS. The emergent surgical airway: cricothyrotomyvs tracheotomy. Int J Oral Maxillofac Surg. 2013;42(2):204-8.

16. Jackson $\mathrm{C}$. High tracheotomy and other errors: the chief causes of chronic laryngeal stenosis. Surg Gynecol Obstet. 1921;32:392-8.

17. Brantigan, CO, Grow JB Sr. Cricothyroidotomy: elective use in respiratory problems requiring tracheostomy. J Thoracic Cardiovasc Surg. 1976;71(1):72-81.

18. François B, Clavel M, Desachy A, Puyraud S, Roustan J, Vignon P. Complications of tracheostomy performed in the ICU: subthyroid tracheostomy vs surgical cricothyroidotomy. Chest. 2003;123(1):151-8

19. Sise MJ, Shackford SR, Cruickshank JC, Murphy G, Fridlund PH. Cricothyroidotomy for long-term tracheal access. Ann Surg. 1984;200(1):13-7.
20. Wang HE, Mann NC, Mears G, Jacobson K, Yealy DM. Out-of-hospital airway management in the United States. Resuscitation. 2011;82(4):378-85.

21. Combes $X$, Jabre $P$, Margenet $A$, Merle JC, Leroux $B$, Dru $M$, et al. Unanticipated difficult airway management in the prehospital emergency setting: prospective validation of an algorithm. Anesthesiology. 2011;114(1):105-10.

22. Warner KJ, Sharar SR, Copass MK, Bulger EM. Prehospital management of the difficult airway: a prospective cohort study. J Emerg Med. 2009;36(3):257-65.

23. Wong $\mathrm{E}, \mathrm{Ng} \mathrm{YY}$. The difficult airway in the emergency department. Int J Emerg Med. 2008;1(2):107-11.

Received in: 11/08/2016

Accepted for publication: 29/09/2016

Conflict of interest: none.

Source of funding: none.

\section{Mailing address:}

Marina Barguil Macêdo

E-mail: marina.bm.15@gmail.com / marinabm@usp.br 